\title{
RESPONSABILIDADE CIVIL DO PRÁTICO: MEDIDAS PROFILÁTICAS À LUZ DO DIREITO COMPARADO, DAS CONVENÇÕES INTERNACIONAIS E DA BOA DOUTRINA MARITIMISTA
}

\section{Lucas Sarmento Pimenta ${ }^{1}$}

\section{Resumo:}

Pretendeu-se lançar luz sobre a responsabilidade civil do prático. Adotou-se o método dialético, com abordagem qualitativa. Primeiro, expôs-se a relação jurídica entre o prático e o armador, assim como a natureza jurídica do serviço de praticagem. Depois, afastou-se a possibilidade responsabilização do prático perante terceiros prejudicados. Ainda, defendeu-se a responsabilidade objetiva do armador, tendo direito à ação de regresso contra o prático, quando o dano for causado por erro específico. Concluiu-se, baseado na experiência de outras nações, que é necessário mudança na legislação especial, sob responsabilidade das Autoridades Legislativa e Marítima, para que haja uma limitação da responsabilidade do prático.

Palavras-Chave: Responsabilidade Civil do Prático. Limitação. Teoria do Erro Genérico. Teoria do Erro Específico. Direito Comparado.

Abstract: It was intended to present the civil liability of the pilot. The dialectical method was adopted. First, the juridical relationship between the pilot and the shipowner was exposed, and also the legal nature of the pilotage service. The possibility of liability of the pilot to third parties was removed. Still, the objective responsibility of the shipowner was defended, having the right to charge the pilot, when the damage is caused by specific error. It was concluded, based on the experience of other nations, that a change in the legislation is necessary to limit the pilot's civil liability.

Keywords: Pilot's Civil Liability. Limitation. Generic Error Theory. Specific Error Theory. Comparative Law.

\section{INTRODUÇÃO}

O prático é o profissional que assessora o comandante do navio, quando da navegação em águas restritas - na entrada e na saída de portos, por exemplo -, por ser conhecedor das particularidades locais, tais como: marés, ventos, profundidades e perigos submersos. Assim, apesar da maior parte da viagem marítima ser conduzida sem o auxílio do prático, uma vez que o navio se aproxima do porto, o comandante necessita dos conhecimentos técnicos e específicos daquele expert.

\footnotetext{
${ }^{1}$ Mestrando em Teorias Jurídicas Contemporâneas pela Faculdade Nacional de Direito - FND/UFRJ. Advogado maritimista. Email: lucas_pimenta96@hotmail.com.
} 
Este artigo tem como pretensão trazer à baila tema pouco explorado pela comunidade jurídica e não delineado no ordenamento jurídico pátrio, qual seja o da responsabilidade civil do prático. Ainda, tem como objetivo alertar as Autoridades Legislativa e Marítima - isto é, os parlamentares e o Comandante da Marinha, respectivamente -, para que, acordando de sono profundo, se pronunciem acerca da necessária limitação da responsabilidade desse profissional.

A discussão se faz relevante por duas razões: a uma, porque, conquanto o Brasil seja um país eminentemente marítimo - vide sua extensa costa - nota-se escassez exacerbada na produção doutrinária acerca da responsabilidade civil do prático; e a duas, porque esses profissionais têm sofrido ações civis indenizatórias por danos causados quando no exercício de seus ofícios (TJSP, 2016) e, portanto, a matéria não pode mais permanecer na obscuridade.

O método utilizado nesta pesquisa foi o dialético, com abordagem qualitativa. Realizou-se pesquisa descritiva e exploratória, com procedimento bibliográfico, com enfoque maior na doutrina do Professor Matusalém Pimenta. Além disso, revelou-se uma visão internacional sobre o tema, por meio da análise das legislações de países de grande tradição marítima.

Nos próximos itens, pretende-se, a princípio, especificar a relação jurídica entre o prático e o armador do navio, assim como a natureza jurídica do serviço de praticagem para, ao depois, tratar das teorias balizadoras da responsabilidade civil do prático. O núcleo do artigo tratará da necessidade urgente de se limitar a responsabilidade deste profissional, por meio de uma mudança na legislação especial, sob pena de danos graves ao interesse público.

\section{O VÍNCULO JURÍDICO ENTRE PRÁTICO E ARMADOR}

A explicação de quem é o protagonista deste trabalho já foi feita na introdução. Cabe, agora, antes de prosseguir, entender quem é aquele que paga pelo serviço desse profissional.

Considera-se armador a pessoa física - empresário individual - ou jurídica sociedade empresária - que arma, ou seja, que prepara o navio para ser empregado em sua finalidade comercial. Note-se que armação não se confunde com propriedade do navio. Nesse sentido, apesar de ser comum no Brasil, não serão todas as vezes que o armador será o dono 
do navio, mas sempre será o titular da função náutica ou da empresa naval (OCTAVIANO MARTINS, 2013, p. 303).

Diz a Lei de Segurança do Tráfego Aquaviário - LESTA, Lei n ${ }^{\circ}$ 9.537/97, que o armador é a "pessoa física ou jurídica que, em seu nome e sob sua responsabilidade, apresta a embarcação com fins comerciais, pondo-a ou não a navegar por sua conta”. Assim, para fins de compreensão deste trabalho, entenda-se que o armador é o empresário que lucra com a atividade comercial do navio e, por isso, precisa de um especialista a bordo - o prático - para auxiliar o seu comandante, quando da entrada da embarcação em águas restritas.

Reconhecidos os personagens marítimos, passa-se à análise da relação jurídica presente entre os dois. Bem compreender o vínculo jurídico existente entre esses dois agentes da indústria naval é essencial para, depois, traçar os limites da responsabilidade civil do prático.

Uma parcela da doutrina entende que a relação existente é estritamente contratual. É o que acredita Carla Gibertoni (2005, p. 138):

\begin{abstract}
Os serviços de praticagem são executados por práticos, mediante acordo de prestação de serviços de praticagem entre a associação ou comissão de práticos e as empresas de navegação ou seus representantes legais, estabelecendo a forma de execução, remuneração e condições de serviço prestado. Não há dúvida quanto à natureza jurídica dessa relação contratual - trata-se de acordo de prestação de serviços - caracterizado por ser um contrato bilateral ou sinalagmático, consensual, oneroso e de execução consecutiva.
\end{abstract}

Por outro lado, há um grupo de doutrinadores, o qual este articulista se filia, liderado por Matusalém Pimenta (2007, p. 124-125), que afirma ser uma relação jurídica híbrida contratual na formação e trabalhista na execução -, não podendo ser classificada como puramente contratual. Segundo Pimenta, a relação contratual estaria mitigada por três motivos: a) inexistência de liberdade de contratar; b) escolha do conteúdo contratual enfraquecida pela legislação especial; e c) supressão do equilíbrio entre as partes. É o que será explicado a seguir.

Primeiro, não há em absoluto liberdade de contratar o prático por parte do armador o serviço de praticagem é obrigatório -, assim como aquele também não pode se recusar a prestar o serviço. Ou seja, a relação entre prático e armador nasce por imposição legal, e não por vontade das partes. Nos moldes do art. $15^{\circ}$ da Lei $n^{\circ}$ 9.537/97: "O prático não pode recusar-se à prestação do serviço de praticagem, sob pena de suspensão do certificado de habilitação ou, em caso de reincidência, cancelamento deste”. Ora, de acordo com Carlos 
Roberto Gonçalves (2016, p. 71), a manifestação de vontade das partes é o requisito mais essencial para a formação do contrato.

Ademais, outra grande característica da maioria dos contratos é a sua bilateralidade (GONÇALVES, 2016, p. 91) quanto à escolha do seus conteúdos. Os contratantes escolhem as obrigações as quais vão se submeter. Nos acordos de praticagem, essa característica é apoucada, vez que o serviço deve ser prestado em conformidade rigorosa com a lei especial supramencionada e os regulamentos pertinentes, como o Regulamento da Lei $\mathrm{n}^{\circ}$ 9.537/97 RLESTA e as Normas e Procedimentos das Capitanias dos Portos e Fluviais.

Outro princípio orientador das relações contratuais é a manutenção do equilíbrio entre as partes (GONÇALVES, 2016, p. 91), que, se descumprido, pode gerar rescisão ou mesmo o reajuste pelo Poder Judiciário. Da mesma maneira, não é o que se apresenta no caso em tela, em que o serviço é prestado sob o regime da hierarquia. Vale lembrar o art. $9^{\circ}$ da LESTA: "Todas as pessoas a bordo estão sujeitas à autoridade do Comandante".

Em resumo, vez que não existe liberdade de contratar, que a escolha do conteúdo é minimizada pela legislação especial e que o serviço é prestado em regime hierárquico, não se deve entender que há relação jurídica puramente contratual. Na verdade, acontece que, em sua formação, a relação é contratual, mas se parece mais com uma relação de trabalho, quando da execução, caracterizando-se, portanto, nas palavras de Pimenta (2007, p. 126), como híbrida.

\section{NATUREZA JURÍDICA DO SERVIÇO DA PRATICAGEM E SUAS CONSEQUENCIAS}

O serviço da praticagem se constitui como um conjunto de atividades profissionais de assessoria ao comandante impostas por lei diante da falta de familiaridade deste último em relação aos perigos e às particularidades locais (OCTAVIANO MARTINS, 2013, p. 549). Essa também é a dicção do art. $12^{\circ}$ da Lei $n^{\circ}$ 9.537/97: “O serviço de praticagem consiste no conjunto de atividades profissionais de assessoria ao Comandante requeridas por força de peculiaridades locais que dificultem a livre e segura movimentação da embarcação”. Dessa forma, por definição legal e doutrinária, a navegação em águas restritas, sob a orientação do prático, tem natureza jurídica de assessoramento.

O Decreto argentino $n^{\circ}$ 2694/91, que trata do serviço de prativagem, identifica essa mesma natureza juríica para o serviço: “Artículo $1^{o}$ - El practicaje y el pilotaje son las tareas 
que realiza a bordo de los buques el personal habilitado para asesorar al capitán en navegación, maniobras y reglamentación, en las zonas declaradas de practicaje o pilotaje obligatorio o facultativo [... $]^{, 2}$.

Ora, se, pela literalidade da lei, o prático é mero assessor do comandante, isto é, não assume, em nenhum momento, o comando do navio, consectário lógico é que o comandante deve ser o responsabilizado pelos eventuais danos causados por erro técnico em acidentes ou fatos da navegação.

Entretanto, não é assim que pensa Gibertoni (2005, p. 139): “Enquanto o prático estiver a bordo, ou de qualquer forma conduzindo a embarcação sob sua responsabilidade, presume-se responsável por qualquer acidente ou fato da navegação, respeitados os limites de suas atribuições."

Haroldo dos Anjos e Carlos Rubens Caminha Gomes (1992, p. 133) discordam da professora:

Há, mesmo entre aqueles que pertencem à comunidade marítima, grande desconhecimento quanto às relações entre capitão e prático. O prático é um auxiliar técnico do comandante na embarcação nas manobras. Não assume, de maneira alguma, o comando da embarcação, nem dirige as manobras e a navegação.

Nesse mesmo diapasão está a legislação do Reino Unido (1987), Estado de grande tradição marítima, chamada, também, de "Pilotage Act":

Liability for ships under compulsory pilotage. The fact that a ship is being navigated in an area and in circumstances in which pilotage is compulsory for it shall not affect any liability of the owner or master of the ship for any loss or damage caused by the ship or by the manner in which it is navigated. ${ }^{3}$

É, também, essa a inteligência do item 0230, a), da Norma da Autoridade Marítima para o Serviço de Praticagem (NORMAM-12): “A presença do Prático a bordo não desobriga o Comandante e sua tripulação dos seus deveres e obrigações para com a segurança da embarcação, devendo as ações do Prático serem monitoradas permanentemente".

De fato, a leitura do texto legal é de clareza meridiana, a teor do artigo. $2^{\circ}$, IV e XV da Lei $\mathrm{n}^{\circ}$ 9.537/97:

\footnotetext{
${ }^{2}$ Artigo $1^{\circ}$ - Praticagem é a tarefa realizada a bordo dos navios pelo pessoal qualificado para assessorar o capitão na navegação, manobras e regulação, nas áreas de praticagem obrigatória ou opcional. (tradução livre do autor)

${ }^{3}$ Responsabilidade por navios sob praticagem obrigatória. $\mathrm{O}$ fato de um navio estar sendo navegado em uma área e em circunstâncias nas quais a praticagem é obrigatória não afetará a responsabilidade do proprietário ou do comandante do navio por qualquer perda ou dano causado pelo navio ou pela maneira como ele é manobrado. (tradução livre do autor)
} 
Art. $2^{\circ}$. Para os efeitos desta Lei, ficam estabelecidos os seguintes conceitos e definições: [...] IV- Comandante (também denominado Mestre, Arrais ou Patrão) tripulante responsável pela operação e manutenção de embarcação, em condições de segurança, extensivas à carga, aos tripulantes e às demais pessoas a bordo; [...] XV- Prático - aquaviário não-tripulante que presta serviços de praticagem embarcado.

Como escolheu o legislador brasileiro, o comandante é o responsável pela direção da embarcação e, outrossim, pela segurança das demais pessoas de bordo, aqui incluído o prático. Sendo assim, o prático presta tão somente assessoramento ao comandante, permanecendo sobre este a direção da embarcação e, portanto, a responsabilidade sobre o serviço de praticagem.

\section{TEORIAS DO ERRO GENÉRICO E DO ERRO ESPECÍFICO}

Se o prático é um mero auxiliar do comandante, estaria então este profissional alheio à qualquer tipo de responsabilidade? Essa não parece ser a solução mais justa, tampouco jurídica para a questão. Nesse sentido, faz-se imperioso o uso das teorias do erro genérico e do erro específico cunhadas por Pimenta (2007, p. 130).

A posição de Pimenta é que haja uma responsabilidade civil compartilhada entre o gestor náutico - o comandante - e o seu auxiliar técnico para manobra e navegação em águas restritas. Deveria, nesse diapasão, existir uma divisão da responsabilidade.

A ideia proposta pelo autor é a de que o comandante deve ser responsabilizado pelos acidentes causados por erro genérico de navegação ou de manobra, mesmo quando sob orientação do prático. De outra mão, deveria recair sobre o assessor técnico a responsabilização, quando os acidentes forem causados por erro específico. Explica-se.

O item 0230, b), 4) da NORMAM-12 assevera que é dever do comandante afastar a assessoria do prático sempre que perceber que esta está pondo em risco a segurança da navegação e das vidas de bordo, in verbis:

"0203 - Compete ao Comandante da embarcação, quando utilizando o Serviço de Praticagem: [...] 4) Dispensar a assessoria do Prático quando convencido que o mesmo está orientando a faina de praticagem de forma perigosa, solicitando, imediatamente, um Prático substituto [...]”.

Pois bem, mais uma vez a norma insiste na noção de que o comandante não deixa de ser o responsável pela direção do navio quando está usufruindo da assessoria técnica do 
prático. Mais que isso, prescreve que é obrigação deste gestor náutico dispensar a assessoria, quando entender que ela é danosa para a boa navegação.

A legislação argentina navega nesse mesmo rumo. Diz o seu Reglamento de los servicios de Practicaje y Pilotaje para los ríos, puertos, pasos y canales de la República Argentina - Decreto 2694/91:

Artículo 13. [...] A pedido del capitán, los prácticos deben dar directamente indicaciones concernientes a la conducción o maniobra del buque, a condición de que el capitán o quien lo reemplace esté presente y pueda, si fuera necesario, intervenir. El capitán es el responsable de la conducción, maniobra y gobierno del buque y su autoridad, en ningún caso se delega en el práctico. ${ }^{4}$

Ocorre que a norma brasileira é silente no sentido de especificar como ocorre o convencimento do comandante de que a assessoria é negativa. Nesse momento, as teorias trazidas por Pimenta põem fim à dúvida.

O comandante, como gestor náutico, está obrigado a conhecer todas as regras de navegação e de boa marinharia, além das características do navio que está sob seu comando. Antes de dar início ao serviço de praticagem, o comandante discute com o prático - por meio do plano de manobra - todo o percurso que será feito sob a orientação de seu auxiliar e o aprova ou não. Uma vez aprovado, autoriza o início da manobra sob assessoria. Desse modo, está o comandante autorizado e apto a interromper a assessoria todas as vezes que o plano de manobra for desrespeitado, garantindo a segurança da embarcação.

Suponha-se, como ilustração, que, em uma parte da navegação, estivesse estipulado mudança de rumo a boreste - à direita. $\mathrm{O}$ prático, contudo, desatento, assessora no sentido de fazer uma curva a bombordo - à esquerda. Ora, o comandante, responsável pela segurança do navio, deve, no mesmo momento, por força de lei, dispensar a assessoria do seu auxiliar e ordenar todo leme ${ }^{5}$ a bombordo. É isso que se espera de um gestor náutico diligente. Mas, se nada disser e a embarcação vier a encalhar, deverá ser responsabilizado pelo dano, pois este terá sido causado pelo que Pimenta classificou como um erro genérico.

É preciso recordar, entretanto, que a assessoria do prático só é necessária, pois há particularidades e perigos locais que não fazem parte do conhecimento do comandante e estão adstritos à sabedoria do auxiliar técnico. Não seria plausível responsabilizar o gestor náutico

\footnotetext{
${ }^{4}$ Artigo 13. A pedido do capitão, os práticos devem dar indicações diretas sobre a condução ou manobra do navio, desde que o capitão ou quem o substitua esteja presente e possa, se necessário, intervir. O capitão é responsável por dirigir, manobrar e governar o navio e sua autoridade, em nenhum caso, é delegada ao prático. (tradução livre do autor)

5 "Aparelho destinado ao governo de uma embarcação (FONSECA, 2002, p. 31)."
} 
por um erro - o qual Pimenta chamou de erro específico - que nem com toda a sua capacidade e experiência acumulada poderia evitar. Senão, estaria esvaziada a importância da profissão do prático.

Imagine-se, por exemplo, que o prático informe uma profundidade incorreta do local de atracação. O comandante, por óbvio, confiará na palavra no prático, pois este é o especialista local. Uma vez que se prove que a causa de um possível acidente foi a informação equivocada transmitida, o prático deverá ser responsabilizado pelo seu erro, diga-se, erro específico, que não poderia ter sido evitado pelo comandante.

Em resumo, a tese de Pimenta (2015, p. 20-22), aplaudida por este articulista, mostra que: se o acidente for causado por erro genérico do prático, ou seja, de fácil percepção do comandante, este deverá ser responsabilizado individualmente, pois deixou de dispensar a assessoria quando deveria; mas, se, por outro lado, o erro do prático for específico, isto é, fora do alcance do conhecimento do comandante, este deverá ser exculpado, responsabilizando-se aquele.

\section{LIMITAÇÃO DA RESPONSABILIDADE CIVIL DO PRÁTICO}

Pois bem, tem-se, então, que tanto o comandante quanto o prático podem ser responsabilizados, dependendo se o erro for genérico ou específico. Até agora, contudo, não se discutiu quem são aqueles que podem requerer indenização por parte dos erros do prático e nem a respeito do limite dessa responsabilidade. É o que será feito nas linhas seguintes.

O profissional protagonista deste artigo sempre foi exonerado de qualquer responsabilidade civil por danos gerados em seu atuar técnico. A razão para este tratamento estava na ideia pacificada na comunidade marítima internacional de que quaisquer danos causados por acidentes da navegação deveriam ser indenizados pelo armador, vez que este trabalha com uma atividade de alto risco. Tanto é assim, que, a fim de resguardarem-se das eventuais falhas do comandante, do prático, dos tripulantes e das demais pessoas de bordo, os armadores contratam grandes coberturas de seguro (PIMENTA, 2007, p. 103).

Os práticos, de outra forma, ficavam submetidos às duras penalidades administrativas. No Brasil, por exemplo, essa competência de responsabilização dos práticos por darem causa a acidentes e fatos na navegação é exercida pelo Tribunal Marítimo, por força do artigo 13, I, da Lei ${ }^{\circ} 2.180 / 54$. 
Ocorre que, no início do século $\mathrm{XX}$, um grupo minoritário ligado ao comércio marítimo internacional começou a argumentar que haveria uma impunidade civil dos práticos neste cenário, o que seria, segundo eles, uma grande injustiça. Os principais países de tradição marítima, em resposta, optaram ou pela irresponsabilidade dos práticos - como a Austrália ou por limitar um valor máximo indenizatório a ser pago pelos assessores técnicos - como França e Inglaterra (PIMENTA, 2007, p. 104).

O Brasil, todavia, não tomou nenhuma atitude. Pelo contrário, até hoje, permanece silente a respeito desta questão. A situação fica ainda pior na medida em que, na omissão da lei, vê-se uma multiplicação de ações civis indenizatórias contra os práticos. O que se pretende mostrar nos próximos itens é que o entendimento minoritário que dá azo a essas responsabilizações navega na contramão da história, desprezando o consenso existente na comunidade jurídica internacional.

\subsection{Responsabilidade civil para com terceiros prejudicados}

Na opinião deste articulista, seguindo os trilhos de Pimenta (2007, p. 135-136), a possível condenação do prático em processo administrativo perante o Tribunal Marítimo quando der causa a incidentes marítimos -, ou, até mesmo, em processo penal, por crimes cometidos no exercício de sua profissão, não abre espaço para que esse profissional sofra ações civis indenizatórias protocoladas por terceiros prejudicados, como quer acreditar uma parcela minoritária de pessoas - armadores e empresas de seguro, especificamente (TJSP, 2016). Nesse passo, faz-se mister expor alguns argumentos que refutem essa posição.

Dos muitos argumentos que poderiam ser apresentados, pinçou-se apenas alguns que foram muito bem explicitados por Pimenta (2007, p. 136-146). Primeiro, a indenização a terceiros não se faz coerente, porque a responsabilidade do armador é objetiva. Nesse momento, é importante trazer à baila os artigos $3^{\circ}$ e $5^{\circ}$ da Convenção de Bruxelas de 1910, da qual o Brasil é signatário:

\footnotetext{
Art. $3^{\circ}$. Se o abalroamento tiver sido causado por culpa de um dos navios, a reparação do danos incumbirá ao navio que tiver incorrido na culpa. [...] Art. $5^{\circ}$. A responsabilidade estabelecida pelas disposições precedentes subsiste no caso em que o abalroamento tenha sido causado por culpa do prático, mesmo nos casos em que a presença deste é obrigatória.
}

Além disso, o art. $1^{\circ}$ da Convenção de Bruxelas de 1924, da qual o Brasil também é signatário, deixou ainda mais cristalina a responsabilidade objetiva do armador: 
Art. $1^{\circ}$. O proprietário de um navio de mar só é responsável até a concorrência do valor do navio, do frete e dos acessórios do navio: $1^{\circ}$ ) Pelas indenizações devidas a terceiros em virtude de prejuízos causados, em terra ou no mar, por fatos ou faltas do capitão, da tripulação, do prático ou de qualquer outra pessoa a serviço do navio. (grifo nosso)

Ainda, para não restar nenhuma sombra de dúvida, a Convenção Internacional sobre Responsabilidade e Compensação por Danos Relativos ao Transporte por Mar de Substâncias Potencialmente Perigosas e Nocivas, assinada em Londres, em 1996, reafirmou a responsabilidade objetiva do armador, impossibilitando que os práticos venham a ser demandados por ações civis indenizatórias, interpostas por terceiros interessados. É como soa o parágrafo $5^{\circ}$ do artigo $7^{\circ}$ desta Convenção: “[...] no claim for compensation for damage under this Convention or otherwise may be made against: [...] (b) the pilot or any other person who, without being a member of the crew, performs services for the ship"

Destarte, percebe-se que as convenções internacionais sempre foram muito claras em estabelecer a responsabilidade civil objetiva do armador quando reclamada por terceiros prejudicados.

Todavia, não é apenas pelas convenções internacionais que se pode chegar a essa conclusão. O nosso ordenamento pátrio, juntamente com a melhor doutrina, se feita a hermenêutica adequada, já são suficientes. Isso porque o prático se enquadra como preposto em sua atividade. É como ensina Cavalieri Filho (2004, p. 198): "Preposto é aquele que presta serviço ou realiza alguma atividade por conta e sob a direção de outrem, podendo essa atividade materializar-se numa função duradoura (permanente) ou num ato isolado (transitório)".

Ora, de fato, o prático se comporta como preposto do armador, pois presta serviço a este, e não a qualquer terceiro que possa ser futuramente prejudicado por seus atos. $\mathrm{O}$ prático é, em verdade, um longa manus do armador, que ajuda este fornecedor a entregar a carga em segurança ao consumidor final - o terceiro o qual o prático não guarda nenhuma relação jurídica.

Parece seguir esta mesma lógica a lei de praticagem (1981) - "Pilotage Act" - do Estado de Washington nos Estados Unidos da América:

Limited liability of pilots and pilot trainees - Liability of vessel, owner, or operator not limited. (2) When a pilot or pilot trainee boards a vessel to provide pilotage

\footnotetext{
6 “[...] nenhum pedido de indenização por danos nos termos desta Convenção ou de outra forma poderá ser feito contra: [...] (b) o prático ou qualquer outra pessoa que, sem ser membro da tripulação, realize serviços para o navio." (tradução livre do autor)
} 
services, that pilot or pilot trainee becomes a servant of the vessel and its owner and operator. Nothing in this section exempts the vessel, its owner, or its operator from liability for damage or loss occasioned by that ship to a person or property on the ground that (a) the ship was piloted by a Washington state licensed pilot or pilot trainee, or (b) the damage or loss was occasioned by the error, omission, fault, or neglect of a Washington state licensed pilot or pilot trainee. (Pilotage Act, RCW 88.16.118, as emended by 2005 c 123). ${ }^{7}$ (grifo nosso)

Essa relação de preposição fica muito clara, vez que o prático está sujeito, por lei, à autoridade do comandante - artigo $9^{\circ}$ da Lei $\mathrm{n}^{\circ}$ 9.537/97 - tendo este, como gestor náutico e maior autoridade a bordo, o dever de fiscalizar e o direito de intervir no serviço do assessor técnico.

Com efeito, pela Teoria da Substituição (CAVALIERI FILHO, 2004, p. 197), o prático substitui a figura do armador, sendo este o comitente e aquele o preposto. Quando o auxiliar técnico está em ação é como se os atos estivessem sendo tomados pelo próprio armador. Nesse sentido, o comitente funciona como garantidor de qualquer possível indenização a terceiros prejudicados, já que o preposto, em regra - e no caso em análise não é diferente - não possui patrimônio suficiente para indenizar.

Convencido, portanto, de que o prático é preposto do armador, não há dúvidas da responsabilidade civil objetiva do último. É o que prescreve o artigo 932, III, combinado com o artigo 933 - todos do Código Civil de 2002:

Art. 932. São também responsáveis pela reparação civil: [...] III - o empregador ou comitente, por seus empregados, serviçais e prepostos, no exercício do trabalho que lhes competir, ou em razão dele. [...] Art. 933. As pessoas indicadas nos incisos I a V do artigo antecedente, ainda que não haja culpa de sua parte, responderão pelos atos praticados pelos terceiros ali referidos. (grifo nosso)

Outro importante argumento em prol da não proposição de ações indenizatórias por parte de terceiros reside no fato inegável de que a atividade comercial executada pelo armador é de altíssimo risco. Isso é facilmente depreendido pela simples observação da atividade de armação, sempre protegida por grandes e complexas coberturas de seguro.

Com isso, seguindo os ensinos da Teoria do Risco (NERY JR., 1984, p. 172), a atividade de armação se enquadra no parágrafo único do artigo 927 do Código Civil: "Haverá obrigação de reparar o dano, independentemente de culpa, nos casos especificados em lei, ou

\footnotetext{
${ }^{7}$ Responsabilidade limitada de práticos e praticantes de prático - Responsabilidade do navio, proprietário ou operador não limitada. (1) (a) Um prático licenciado para agir como tal pelo Estado de Washington [...] não deve ser responsável por danos superiores ao valor de cinco mil dólares por danos ou perdas ocasionados por erros, omissões, falhas ou negligência de práticos ou praticantes de prático na execução de serviços de praticagem ou treinamento de práticos, exceto quando possa surgir em razão de conduta dolosa ou negligência grave do prático (Lei de Praticagem, RCW 88.16.118, conforme emenda de 2005 c 123). (tradução livre do autor)
} 
quando a atividade normalmente desenvolvida pelo autor do dano implicar, por sua natureza, risco para os direitos de outrem". Logo, mais uma vez, nota-se a responsabilidade objetiva do armador em face de danos causados a terceiros por erro do prático.

Essa realidade foi constatada, também, por Octaviano Martins (2013, p. 322-323):

Em sede de responsabilidade do armador pelos acidentes e fatos da navegação e
pelas avarias marítimas, tem-se evidenciado, no âmbito cível e administrativo, a
tendência geral dos tribunais em consagrar a teoria da responsabilidade objetiva ou
do risco profissional do armador. Considerando o armador o empresário da
navegação, tem-lhe sido imputáveis responsabilidades independentemente de culpa
pelas avarias marítimas e pelos acidentes e fatos da navegação.

Ainda, não se pode furtar a percepção do contrassenso que seria responsabilizar o prático civilmente perante terceiros, por alguns motivos: de início, porque os possíveis danos causados por práticos já estão cobertos pelas apólices de seguros do armador; depois, porque a responsabilização do assessor técnico elevaria os custos dos armadores no Brasil, vez que o serviço de praticagem se tornaria mais caro; e, por fim, porque seria ignorar a história, já que esse sistema falhou nos Estados Unidos da América, preferindo os próprios armadores pagar um preço mais baixo pela assessoria técnica, do que os práticos terem de arcar com indenizações perante terceiros (PIMENTA, 2007, p. 143).

Finalmente, faz-se imperioso revisitar a função do prático a bordo. Este profissional, no seu exercício, funciona como um verdadeiro gerenciador de risco, haja vista a alta periculosidade da atividade comercial de armação. Por isso, não é de se espantar que, vez ou outra, acidentes possam ocorrer - o que, claro, já é esperado pelo armador.

Seria uma grande irresponsabilidade pensar que o prático poderia exercer o seu labor tranquilamente, quando, por exemplo, está assessorando a navegação de um navio petroleiro, completamente carregado de óleo, pela Baía de Guanabara, no Rio de Janeiro, enquanto qualquer acidente poderá lhe custar indenizações da cifra de bilhões de reais. É assim também o entendimento de Luiz Carlos de Araújo Salviano (1999, p. 11), ex-juiz do Tribunal Marítimo:

É importante notar que o Tribunal Marítimo, em seu Parecer sobre a matéria, alerta que a simples possibilidade de dilapidação dos patrimônios pessoais dos práticos, construídos com o esforço da dura labuta diária a bordo dos navios, em decorrência de uma indenização vultosa, resultante de Ação de Responsabilidade Civil, originadas em fatos e acidentes da navegação, certamente provoca impacto negativo em tais profissionais, ensejando insegurança e intranquilidade, quando do desempenho de suas funções como assistente técnico do comandante a bordo, podendo se tornar em um fator humano contribuinte para a ocorrência de eventos danosos à segurança da navegação e de consequências nefastas para o contexto geral da navegação comercial. 
Como bem alertou Salviano, responsabilizar o prático teria o efeito contrário do esperado. O psicológico daqueles profissionais seria tão afetado, vide a desumanidade estampada a qual estariam submetidos, que ficariam divididos entre gerenciar os riscos do armador e os seus próprios riscos. Desse modo, estaria esvaziada a função do prático.

Do sobredito, conclui-se que, a contrário do desejo de uma parcela minoritária da comunidade marítima brasileira, o protagonista deste artigo não deve ser responsabilizado civilmente perante terceiros, em respeito a fatores legais, históricos e humanos, explicados ao longo desta seção secundária.

\subsection{Responsabilidade civil para com o armador}

O fato do prático não poder ser responsabilizado perante terceiros não afasta, por óbvio, o direito de regresso do armador. O direito de regresso consiste na possibilidade do terceiro que suportou a indenização ser ressarcido, por meio de ação própria, pelo autor material do dano. Ou seja, é uma maneira do Poder Judiciário tentar - porque nem sempre o autor tem patrimônio suficiente - restabelecer o equilíbrio patrimonial (CARVALHO FILHO, 2015, p. 606).

O direito de regresso, com se vê, é um direito necessário para se alcançar a justiça. Tanto é assim que o legislador decidiu gravar o artigo 934 no Código Civil, garantindo a ação de regresso: "Art. 934. Aquele que ressarcir o dano causado por outrem pode reaver o que houver pago daquele por quem pagou, salvo se o causador do dano for descendente seu, absoluta ou relativamente incapaz".

Haverá, contudo, levando em consideração o raciocínio construído ao longo deste artigo, apenas uma configuração em que o prático deverá ressarcir o armador, segundo a pena de Pimenta (2007, p. 148): quando o Tribunal Marítimo - seu acórdão servirá de prova robusta na área cível, segundo o artigo 18 da Lei no 2.180/54 - apontar aquele como o único responsável pelo dano e sendo a causa determinante do acidente um erro específico, o qual não poderia ser evitado pelo comandante.

Mas, se a Corte Marítima, ao revés, entender que houve outros responsáveis além do prático, como comandante, agentes etc., será aplicada a Teoria da Causalidade Adequada prevalecente em sede de responsabilidade civil (CAVALIERI FILHO, 2004, p. 85), recaindo a responsabilidade apenas sobre o comandante. Assim, ainda que se comprove erro genérico 
do prático, a causa adequada para o dano terá sido a omissão do comandante, que não dispensou a sua assessoria como lhe é exigido.

Foi nesse mesmo sentido que os desembargadores do Tribunal de Justiça do Estado de São Paulo proferiram este acórdão, utilizando, no silêncio da lei, as teorias criadas por Pimenta como fundamentação:

APELAÇÃO. AÇÃO REGRESSIVA. DANOS EM EMBARCAÇÃO. SEGURO MARÍTIMO. ACIDENTE MARÍTIMO. RESPONSABILIDADE CIVIL DO PRÁtICO. EXCEÇÃO CONDUTA CULPOSA REPELIDA. NEXO DE CAUSALIDADE AFASTADO. DEVER DE INDENIZAR NÃO APURADO. RESPONSABILIDADE DO ARMADOR E DO COMANDANTE. NORMAS MARÍTIMAS. ÔNUS DA PROVA. HONORÁRIOS DE SUCUMBÊNCIA. REDUÇÃO. EQUIDADE.

[...] Não bastasse a conclusão do Tribunal Marítimo, as provas colacionadas não permitem concluir a culpa do prático para o sinistro. Nas exatas palavras da decisão da R. Primeira Instância, não ficou demonstrado o "erro específico" vinculado à atividade do prático inviável, portanto, a responsabilidade regressiva. [...] O sinistro ocorreu de erro genérico, imputável ao responsável pela embarcação e, consequentemente ao armador isto é, culpa exclusiva da própria vítima (segurada), em que a recorrente se sub-rogou, tornando inviável a pretensão regressiva. (TJSP, 2016)

No caso acima, uma seguradora de rebocadores tentava ação de regresso contra o prático, alegando erro de manobra deste. Os desembargadores, acertadamente, negaram o pedido, pois o acidente, como ficou demonstrado, ocorreu por erro genérico.

Mesmo após essas limitações, fato é que o prático ainda poderá responder por ações de regresso em valores que alcançam os bilhões de dólares, tendo em conta as grandiosas cifras que envolvem o transporte marítimo. Restaria, por conseguinte, ao juiz a aplicação do parágrafo único do artigo 944 do Código Civil: "Se houver excessiva desproporção entre a gravidade da culpa e o dano, poderá o juiz reduzir, eqüitativamente, a indenização".

Ainda assim, o prático não teria tranquilidade para trabalhar, pois, a qualquer momento, pelo clima se insegurança instalado - vez que há pouco conhecimento desta profissão por parte dos juízes -, poderia ter seu patrimônio dilapidado. Faz-se necessário, portanto, que, com urgência, as Autoridades Marítima e Legislativa, estabeleçam, em lei, um valor suportável, para que se limite a responsabilidade civil do prático. 


\subsection{Limitação da responsabilidade civil nas legislações alienígenas}

Quando se faz uma análise, em sede de Direito Comparado, acerca da responsabilidade civil do prático, confronta-se com uma triste realidade: o Brasil é um país extremamente atrasado em relação a essa questão, já há muito tempo solucionado por várias outras nações.

De fato, uma vez que esta questão está pacificada na comunidade jurídica internacional há anos - no sentido da limitação da responsabilidade civil tanto do prático quanto do armador -, os países de tradição marítima decidiram positivar esta restrição em seus respectivos ordenamentos jurídicos. O entendimento amplamente majoritário é o de que a limitação da responsabilidade do prático impede que haja, como analisado anteriormente (ver 4.1), uma superposição de seguros e, consequentemente, a elevação dos preços e o desagrado geral.

A regra geral, assim, foi que os países decidiram por limitar a responsabilidade civil do prático. Note-se, por exemplo, o Reino Unido que limita a responsabilidade civil do prático em mil libras, além do valor cobrado pelo serviço. É esta a inteligência da lei inglesa de praticagem de 1987 (Pilotage Act, 1987), no seu capítulo 22:

22 Limitation of liability in respect of pilots. (1) The liability of an authorised pilot for any loss or damage caused by any act or omission of his whilst acting as such a pilot shall not exceed $£ 1,000$ and the amount of the pilotage charges in respect of the voyage during which the liability arose. $[. . .]^{8}$ (grifo nosso)

É de se impressionar que desde 1987, ou seja, há trinta e dois anos atrás o Reino Unido já havia solucionado esse problema, enquanto, até o momento em que este artigo está sendo escrito, o Brasil nunca sequer se pronunciou sobre o caso.

Mas os exemplos mostram que as limitações começaram ainda antes. Observe-se o caso do Canadá que, desde de 1972, já havia superado este empecilho. É o que prescreve o artigo 40 (1) de sua legislação de praticagem: "Limitation de la responsabilité. 40 (1) Le montant maximal des dommages-intérêts qu'un pilote breveté est tenu de payer pour les dommages ou pertes causés par sa faute, sa négligence ou son impéritie est de mille dollars." (Loi sur le pilotagem, 1972)

\footnotetext{
${ }^{8}$ Limitação de responsabilidade em relação aos práticos. (1) A responsabilidade de um prático autorizado por qualquer perda ou dano causado por qualquer ato ou omissão sua enquanto prático não deverá exceder $£ 1.000$ e o valor das taxas de praticagem em relação à viagem durante a qual a responsabilidade surgiu. [...] (tradução livre do autor)
} 
Não foi diferente na região de Hong Kong (Pilotage Ordenance, 1982) que já na década de 1980 tinha o limite estabelecido de responsabilização por parte de práticos:

24A. Liability of licensed pilot for neglect or want of skill. A licensed pilot shall not be liable in damages for neglect or want of skill on his part while piloting a ship for any amount exceeding in the aggregate the sum of \$1,000 and the amount of pilotage dues payable in respect of pilotage services rendered by him for that ship. ${ }^{9}$ (grifo nosso)

O Estados Unidos, por sua vez, possui organização diferente. As legislações de práticos são diferentes em cada Estado americano e, claro, nem todos possuem leis desse tipo, já que muitos não possuem áreas navegáveis que necessitem a presença daquele profissional. Independentemente do Estado, percebe-se que a limitação da responsabilidade foi, mais uma vez, entendida como a opção mais adequada. Para ilustrar, segue-se trecho da legislação do Estado de Washington - Pilotage Act, 1981 -, emendada em 2005 para incluir o seguinte:

Limited liability of pilots and pilot trainees - Liability of vessel, owner, or operator not limited. (1) (a) A pilot licensed to act as such by the state of Washington [...] shall not be liable for damages in excess of the amount of five thousand dollars for damages or loss occasioned by a pilot's or pilot trainee's errors, omissions, fault, or neglect in the performance of pilotage or pilot training services, except as may arise by reason of the willful misconduct or gross negligence of the pilot (Pilotage Act, $R C W 88.16 .118$, as emended by 2005 c 123). ${ }^{10}$ (grifo nosso)

Pelo exposto acima, é nítida a opção dos países de tradição marítimo por limitar a responsabilidade civil do prático. Alguns poucos países, entretanto, como a Austrália (2006), decidiram irresponsabilizar civilmente o prático em quaisquer circunstâncias.

A verdade é que a Austrália navegava em outro sentido, com a sua lei marítima de 1988, que trazia uma limitação para a responsabilidade do auxiliar técnico. É o que se observa: "Marine Act 1988 104. Limited liability of pilots. A pilot is not liable in negligence in respect of the voyage on which the pilot is engaged for more than $\mathbf{\$ 2 0 0}$ plus the amount of pilotage in respect of that Voyage" ${ }^{, 11}$ (grifo nosso). Contudo, esta lei sofreu uma emenda em

\footnotetext{
${ }^{9}$ Responsabilidade do prático licenciado por negligência ou falta de habilidade. Um prático licenciado não será responsável por danos causados por negligência ou falta de habilidade da sua parte enquanto pilota um navio por qualquer quantia que exceda no total a soma de $\$ 1.000$ e o montante de taxas de pilotagem a pagar pelos serviços de praticagem prestados por ele ao navio. (tradução livre do autor)

${ }^{10}$ Responsabilidade limitada de práticos e praticantes de prático - Responsabilidade do navio, proprietário ou operador não limitada. (1) (a) Um prático licenciado para agir como tal pelo Estado de Washington [...] não deve ser responsável por danos superiores ao valor de cinco mil dólares por danos ou perdas ocasionados por erros, omissões, falhas ou negligência de práticos ou praticantes de prático na execução de serviços de praticagem ou treinamento de práticos, exceto quando possa surgir em razão de conduta dolosa ou negligência grave do prático (Lei de Praticagem, RCW 88.16.118, conforme emenda de 2005 c 123). (tradução livre do autor)

${ }^{11}$ Lei Marítima de 1988. Responsabilidade limitada dos práticos. Um prático não é responsável por negligência em relação à viagem em que é contratado como prático por mais de \$200 mais a quantidade do valor de serviço de praticagem dessa viagem. (tradução livre do autor)
} 
2006, optando pela não responsabilização dos práticos. É como soa este fragmento da emenda legislativa marítima:

\begin{abstract}
Maritime Legislation Amendment Act [...] Subsection $410 B$ (2) [...] (3) If a pilot: (a) does an act, issues an instruction, or provides information or advice in or in relation to the pilotage of a ship; and (b) that act is done, that instruction is issued, or that information or advice is provided, in the course of the pilot's duty and in good faith; and (c) that act, instruction, information or advice affects the navigation of the ship so that loss or damage is caused to or by the ship; neither the pilot nor any pilotage provider responsible for the provision of the pilot's services is liable in civil proceedings for that loss or damage. ${ }^{12}$ (grifo nosso)
\end{abstract}

Tem-se, portanto, que a Austrália decidiu por retirar a responsabilidade civil do prático, mantendo-se, apenas, as reponsabilidades administrativas e penais.

O Direito espanhol, por sua vez, distoa completamente dos parâmetros adotados pelos países já analisados. Veja-se o artigo 281 da Ley de Puertos del Estado y de la Marina Mercante ("Lei de Portos Estaduais e da Marinha Mercante") de 2003, modificada pela Lei $\mathrm{n}^{\circ}$ 33/2010:

Artículo 281. Responsabilidad. La responsabilidad civil en la que pudieran incurrir los prácticos o las Autoridades Portuarias en la gestión del servicio de practicaje no podrá superar, en caso de siniestro, la cuantía de veinte euros por unidad de arqueo bruto del buque para el que prestan el servicio, con un tope máximo de un millón de euros. $[\ldots]^{13}$ (grifo nosso)

Como se observa, a lei espanhola estipula um impressionante limite de responsabilidade de um milhão de euros. Mediante a altíssima quantia estipulada, imagina-se que o legislador tenha confundido a atividade do prático com a do armador. Como já foi demonstrado (ver 4.1), o prático é apenas o limitador dos riscos inerentes à armação, não podendo, de maneira alguma, suportar os valores estratosféricos dessa atividade.

O Brasil deve, ao contrário, inspirar-se em países como a Argentina, que, percebendo o atraso de sua legislação, decidiu, em 2017, a adotar, em sua Ley de la Navegacion ("Lei da Navegação") de 1973, um limite máximo para a responsabilidade civil do prático:

\footnotetext{
${ }^{12}$ Emenda à Legislação Marítima [...] Subsecção 410B (2) [...] (3) Se um prático: (a) faz um ato, emite uma instrução, ou fornece informação ou aconselhamento em ou em relação à praticagem de um barco; e (b) aquele ato é feito, aquela instrução é emitida, ou aquela informação ou conselho é provida, no curso do dever do prático e de boa fé; e (c) esse ato, instrução, informação ou conselho afeta a navegação do navio de modo que a perda ou dano seja causado para ou pelo navio; nem o prático nem qualquer prestador de praticagem responsável pela prestação dos serviços do prático são responsáveis em processos civis por essa perda ou dano. (tradução livre do autor)

${ }^{13}$ Artigo 281. Responsabilidade. A responsabilidade civil constituída pelos práticos ou pelas Autoridades Portuárias na gestão do serviço de pilotagem não pode exceder, em caso de acidente, o montante de vinte euros por unidade de arqueação bruta da embarcação para a qual prestam o serviço, com um limite máximo de um milhão de euros. [...] (tradução livre do autor)
} 
Artículo 145 - [...] La responsabilidad civil por los servicios de practicaje y pilotaje se encuentra limitada a la cantidad de ciento sesenta (160) argentinos oro, salvo en casos de dolo en que la responsabilidad será ilimitada (valor equivalente a 50 mil dólares). ${ }^{14}$

Como exemplo final, e mais relevante, traz-se a legislação francesa (1969) que, como nenhuma outra, emoldura, com riqueza de detalhes, os limites para a responsabilização do civil do prático.

Loi $n^{\circ}$ 69-8 du 3 janvier 1969. [...] Section II : Des pilotes. Article 18. Le pilote n'est pas responsable envers les tiers des dommages causés au cours des opérations de pilotage. Il doit contribuer à la réparation, dans ses rapports avec l'armateur $d u$ navire piloté, dans la mesure où celui-ci établit que le dommage est dû̀ à une faute du pilote. [...] Article 20. Tout pilote doit fournir un cautionnement. ${ }^{15}$

Obeserva-se, que todo o prático deverá fornecer, então, fornecer uma caução como garantia. Assim, um decreto de 1986, em complemente à esta lei específica, estabele uma instituição responsável pelo depósito da caução exigida: “Arrêté du 3 septembre 1986. Article premier - La caísse de La fedération française de syndicats profissionnels de pilotes maritimes, domicilieé 74, rue du Rocher 75008 Paris, est agréé comme caísse de garantie du cautionnement exigeé des pilotes maritimes par La loi. ${ }^{16,}$

Ademais, um decreto de 1999 fixa o valor exato a ser depositado como caução pela instituição, limitando, portanto, a responsabilidade do prático a valores condizentes com o seu ofício. É como se observa: "Arrête du premier juillet 1999. Art. Premier - Le cautionnement des pilotes maritimes est fixe comme suit: per lês stations dont la liste est annexée au présent arrêté, Le montant de cautinnement est de 65.595,70 $F^{, 17}$ - hoje, este valor esquivale a dez mil euros.

Em suma, ficou mais que demonstrada a demora do Brasil em se pronunciar a respeito desta questão. Evidenciou-se que a ampla maioria das nações de alta relevância no cenário marítmo optou pela limitação da responsabilidade civil do prático. Seguindo o bom

\footnotetext{
${ }^{14}$ Artigo 145 - [...] A responsabilidade civil pelos serviços de praticagem é limitada ao montante de 160 (cento e sessenta) de ouro argentino, exceto nos casos de dolo nos quais a responsabilidade será ilimitada. (tradução livre do autor)

${ }^{15}$ Lei no ${ }^{\circ}$ 69-8 de 3 de janeiro de 1969. [...] Seção II: Dos Práticos. Art. 18. O prático não é responsável perante terceiros pelos danos causados durante as operações de praticagem. Ele deve contribuir para o reparo, em suas relações com o proprietário do navio pilotado, na medida em que ele estabelece que o dano é devido a uma falha do prático. [...] Artigo 20. Todo prático deve fornecer uma caução. (tradução livre do autor)

${ }^{16}$ Decreto de 3 de setembro de 1986. Artigo 1 - O caixa da federação francesa de sindicatos profissionais de práticos, domicílio 74, rue du Rocher 75008 Paris fica estabelecido como o caixa de garantia exigida dos práticos pela lei. (tradução livre do autor)

${ }^{17}$ Decreto de primeiro de julho de 1999. Art. Primeiro - A caução dos práticos é fixada da seguinte forma: para as estações cuja lista é anexada ao presente pedido, a quantidade de cautela é 65.595,70 F. (tradução livre do autor)
} 
exemplo, da mesma forma, devem Autoridades Marítima e Legislativa fixar um preço, ajustável anualmente e compatível com a sua profissão, para a indenização civil por parte do prático.

\section{CONSIDERAÇÕES FINAIS}

Por todo o exposto, restou claro, pelas teorias do risco e da causalidade adequada, que a responsabilidade civil do armador é objetiva. Não está excluído, no entanto, seu direito a mover ação regressiva contra o prático em caso de dano causado por erro específico deste, o que leva este auxiliar técnico a condições delicadas e inseguras.

Como ficou demonstrado, o prático é um gerenciador de riscos, devendo ter total tranquilidade no exercício de sua função, a fim de proteger o patrimônio do armador, de terceiros, as vidas de bordo, as instalações portuárias e o meio ambiente marinho. Nesse sentido, não pode esse profissional ser atacado por pressões psicológicas que gerem nele necessidade de se preocupar com o seu próprio patrimônio, podendo gerar desdobramentos nocivos à segurança da navegação.

Uma vez crescentes os números de ações civis indenizatórias contra esses profissionais, aumenta-se a sensação de insegurança e põe-se em risco a segurança da navegação. Devem, portanto, o quanto antes, as Autoridades Marítima e Legislativa, seguindo a doutrina de Pimenta e o bom exemplo das nações de tradição marítima, extinguirem a lacuna legal presente hoje, limitando a responsabilidade civil do prático a valores acessíveis e coerentes com a sua profissão.

É o desejo deste articulista ter contribuído de alguma forma para que as comunidades jurídica e marítima possam debater sobre o tema, e, se não adotarem a tese aqui defendida, que, ao menos, retirem a questão deste silêncio ensurdecedor.

\section{REFERÊNCIAS}

ANJOS, J. Haroldo dos; GOMES, C. R. Caminha. Curso de Direito Marítimo. Rio de Janeiro: Renovar, 1992.

ARGENTINA. Decreto 2694/91. Disponível em:http://servicios.infoleg.gob.ar/infolegInternet /anexos/15000-19999/16701/norma.htm. Acesso em: 21 jul. 2019. 
ARGENTINA. Ley de la Navegacion, 1973. Disponível em: http://servicios.infoleg.gob.ar/ infolegInternet/anexos/40000-44999/43550/texact.htm. Acesso em: 21 jul. 2019.

AUSTRÁLIA. Marine Act, 1988. Disponível em: https http://www.legislation.vic.gov.au/ domino/Web_Notes/LDMS/LTObject_Store/LTObjSt3.nsf/d1a8d8a9bed958efca2576160004 2ef5/8182a00eb95bf84eca25776100265410/\$FILE/88-52a049.pdf. Acesso em: 21 jul. 2019.

AUSTRÁliA. Maritime Legislation Amendment Act, 2006. Disponível em: https://www. legislation.gov.au/Details/C2006A00024. Acesso em: 21 jul. 2019.

BRASIL. Diretoria de Portos e Costas. NORMAM-12/DPC. Disponível em: https://www.mar inha.mil.br/dpc/sites/www.marinha.mil.br.dpc/files/processoselecao/normam12.pdf. Acesso em: 21 jul. 2019.

BRASIL. Diretoria de Portos e Costas. NORMAM-13/DPC. Disponível em: https://www.mar inha.mil.br/dellaguna/sites/www.marinha.mil.br.dellaguna/files/Downloads/N-13.pdf. Acesso em: 21 jul. 2019.

BRASIL. Lei $\mathrm{n}^{\circ} 2.180$ de 5 de fevereiro de 1954. Disponível em: http://www.planalto.gov.br /ccivil_03/LEIS/L2180.htm. Acesso em: 21 jul. 2019.

BRASIL. Lei $\mathrm{n}^{\circ} 9.537$ de 11 de dezembro de 1997. Disponível em: http://www.planalto.gov .br/ccivil_03/leis/19537.htm. Acesso em: 21 jul. 2019.

BRASIL. Lei n ${ }^{\circ} 10.406$, de 10 de janeiro de 2002. Disponível em: http://www.planalto .gov.br/ccivil_03/leis/2002/110406.htm. Acesso em: 21 jul. 2019.

BRUXELAS. Convenção Internacional para a Unificação de Certas Regras em Matéria de Conhecimentos. Assinada em 24 ago. 1924. Disponível em: https://www.porlogis.pt/admin /ficheiros_projectos/201201311145-convencaao_bruxelas.pdf. Acesso em: 21 jul. 2019.

BRUXELAS. Convenção para a Unificação de Certas Regras em Matéria de Abalroação . Assinada em 23 set. 1910. Disponível em: https://bo.io.gov.mo/bo/ i/35/19/ou t01.asp\#ptg. Acesso em: 21 jul. 2019.

CANADÁ. Loi sur le pilotagem, 1972. Disponível em: Disponível em: https://bo.io.gov.mo /bo / i/35/19/ou t01.asp\#ptg. Acesso em: 21 jul. 2019. Acesso em: 21 jul. 2019.

CARVAlHO FILHO, José dos Santos. Manual de Direito Administrativo. 29a ed. São Paulo: Atlas, 2015.

CAVALIERI FILHO, Sergio. Programa de Responsabilidade Civil. $5^{\text {a }}$ ed. rev. aum. Atual. São Paulo: Malheiros, 2004.

ESPANHA. Ley $n^{\circ}$ 48/2003. Ley de Puertos del Estado y de la Marina Mercante. Disponível em: https://www.boe.es/eli/es/rdlg/2011/09/05/2/con. Acesso em: 21 jul. 2019. 
FONSECA, Maurílio M. Arte Naval. Vol. 1. $6^{\text {a }}$ ed. Rio de Janeiro: Serviço de Documentação da Marinha, 2002.

FRANÇA. Arrêté du premier juillet 1999. Disponível em: https://www.legifrance.gouv.fr/ affichTexte.do?cidTexte=JORFTEXT000000577751\&categorieLien=id. Acesso em: 21 jul. 2019.

FRANÇA. Arrêté du 3 septembre 1986. Disponível em: https://www.legifrance.gouv.fr/affic hTexte.do;jsessionid=E5AA17E061A30144C1E354E1FF321731.tpdjo03v_1 ?cidTexte=JOR FTEXT000000317959\&categorieLien=id. Acesso em: 21 jul. 2019.

FRANÇA. Loi $n^{\circ}$ 69-8 du 3 janvier 1969. Disponível em: https://www.legifrance.gouv.fr/ affichTexte.do?cidTexte=JORFTEXT000000878390\&categorieLien=cid. Acesso em: 21 jul. 2019.

GIBERTONI. C. A. Comitre. Teoria e Prática do Direito Marítimo. $2^{\mathrm{a}}$ ed. rev. e atual. Rio de Janeiro: Renovar, 2005.

GONÇALVES, Carlos Roberto. Direito Civil Brasileiro. São Paulo: Saraiva, 2016.

HONG KONG. Pilotage Ordenance, 1982. Disponível em: https://www.elegislation.gov.hk/ hk/cap84. Acesso em: 21 jul. 2019. Acesso em: 21 jul. 2019.

LONDRES. Convenção Internacional sobre responsabilidade e compensação por danos relativos ao transporte por mar de substâncias potencialmente perigosas e nocivas. 1996. Disponível em: http://www.imo.org/en/OurWork/Legal/HNS/Documents/HNS\%20Consolida ted\%20text.pdf. Acesso em: 21 jul. 2019.

NERY JR., Nelson. Responsabilidade civil por dano ecológico e a ação civil pública. In: Revista Justitia, n. 126, São Paulo, jul./set. 1984.

OCTAVIANO MARTINS, Eliane. M. Curso de Direito Marítimo. Vol. I. 4ª ed. Barueri: Manole, 2013.

PIMENTA, Matusalém Gonçalves. Responsabilidade Civil do Prático. Rio de Janeiro: Lumen Juris, 2007.

REINO UNIDO. Pilotage Act, 1987. Disponível em: https://www.legislation.gov.uk/ukpga /1987/21/contents. Acesso em: 21 jul. 2019.

SALVIANO, Luiz Carlos de Araújo. A Responsabilidade Civil na Navegação Marítima Segundo a Legislação e Doutrina Brasileiras. Revista Embarque do Prático, ano II, $\mathrm{n}^{\circ}$ 4. Rio de Janeiro: CONAPRA, 1999.

TJSP. Apelação Cível. 0009870-18.2012.8.26.0562. Relatora: Maria Lúcia Pizzotti: DJ 13/04/2016. Disponível em: https://esaj.tjsp.jus.br/cjsg/getArquivo.do;jsessionid=0B4A 5EBC6026B0E37857BA5E226A26B3.cjsg1 ?conversationId=\&cdAcordao=9978305\&cdForo 
$=0 \&$ uuidCaptcha $=$ sajcaptcha_644265b2fbe24580b637543abbbbad04\&vlCaptcha=mtuq\&nov oVlCaptcha=. Acesso em: 21 jul. 2019.

VENOSA., Silvio de Salvo. Direito Civil: responsabilidade civil. $5^{\text {a }}$ ed. São Paulo: Atlas, 2005 .

WASHINGTON. Pilotage Act, 1981. Disponível em: https://app.leg.wa.gov/RCW/default.asp $\mathrm{x}$ ?cite=88.16.118. Acesso em: 21 jul. 2019. 